\title{
A popularização da canoagem: o caso de Piracicaba
}

Nelson Marcelino Denis Roberto Terezanit

\begin{abstract}
Resumo: Oriunda do cotidiano da cultura popular, seja como atividade utilitária, seja como atividade lúdica, a canoagem se insere hoje, como lazer e esporte, na nossa sociedade, mas necessita de políticas públicas, para ser democratizada, tendo em vista uma série de barreiras socioculturais que cercam seu desenvolvimento. A experiência de Piracicaba-SP, aqui analisada, a partir de estudo de caso, baseado em análise de conteúdo documental, demonstra que isso é possível, se a canoagem for integrada a uma política pública municipal de Esporte e Lazer, e neste último aspecto, encarada na suas primeiras fases, a partir do componente lúdico da cultura.
\end{abstract} Palavras-chave: lazer, esporte, políticas públicas, canoagem.

\section{Introdução}

Vivemos em um país predominantemente de clima tropical, contando com a abundância de recursos fluviais como rios e lagos, além de toda costa leste banhada pelo Oceano Atlântico. De acordo com esses aspectos, podemos concluir que desfrutamos de condicões ambientais privilegiadas para a prática da canoagem. Oriunda do cotidiano da cultura popular, seja como atividade utilitária, seja como atividade lúdica, a canoagem se insere hoje como lazer e esporte na nossa sociedade pós-industrial, de características urbanas, mas necessita de políticas públicas, governamentais e da sociedade civil organizada, para ser democratizada no Brasil, tendo em vista uma série de barreiras socioculturais que tornam suas águas turbulentas. A experiência de Piracicaba-SP, aqui analisada, a partir de pesquisa documental ${ }^{1}$ demonstra que isso é possível, se a canoagem for integrada a uma política pública municipal de Esporte e Lazer,

1 Para a pesquisa foram utilizados: como método - o estudo de caso (BRUYNE et al., 1991), e como técnicas - de amostragem - para determinação da cidade - não probabilística, por critérios de representatividade e acessibilidade, e de análise a análise de conteúdo (GIL, 1991). O texto completo da pesquisa pode ser verificado em Terezani (2004).

Movimento, Porto Alegre, v. 11, n. 3, p. 67-88, setembro/dezembro de 2005 
considerada enquanto lazer e esporte e, neste último aspecto, encarada na suas primeiras fases (iniciação e aperfeiçoamento), a partir do componente lúdico da cultura, que vem conquistando cada vez mais adeptos.

É, pois, a partir da manifestação cultural lúdica (HUIZINGA, 1993; ARIÉS 1976; PERROTI, 1982; MARCELLINO, 1990), do jogo, como fundamento do esporte, que se devem buscar os elementos para a sua popularização, pelo menos, num primeiro momento, fundamentando a ação no prazer de sua vivência.

Considerando o componente lúdico da cultura no esporte canoagem é fundamental que sejam destacados os seus elementos elencados por Caillois (1990), especialmente agôn e ilinx, que o caracteriza como competitivo e de aventura, buscando o equilíbrio nas políticas de popularização, entre a canoagem/lazer e a canoagem/ competição.

As políticas públicas nacionais precisam romper com a gestão burocrática, destacada por Zingoni (2003) e procurar, no âmbito municipal, a gestão participativa em rede Zingoni (2003).

\section{A estrutura organizacional da canoagem brasileira}

Desde que foi organizada no país, como esporte, em meados da década de 1970, a canoagem vem contabilizando um número crescente de praticantes, estimado, atualmente, em cem mil adeptos. Após um longo período para a afirmação da modalidade, o impulso só surgiu, em 1985, com a criação da Associação Brasileira de Canoagem (A.B.C.), órgão administrativo, de caráter nacional. Este órgão veio a se transformar, em 1989, no município de Resende RJ, em Confederação Brasileira de Canoagem (CBCa), passando atualmente a exercer sua organização e funcionamento autônomos, na cidade paranaense de Curitiba. Nestas circunstâncias, a CBCa apresenta-se como órgão máximo na representatividade de qualquer manifestação da canoagem brasileira, em âmbito nacional e internacional, seja em relação ao Ministério do Esporte, do Governo Federal, ou ao Comitê Olímpico Brasileiro (C.O.B.). Também, é filiada às entidades internacionais de canoagem.

Assim, compreendemos que qualquer programa idealizado para o crescimento e a propagação da modalidade canoagem, entendida como esporte, em todo território nacional deva ser expedido, aceito ou desenvolvido pela CBCa. Dessa forma, as Federações Estaduais

Movimento, Porto Alegre, v. 11, n. 3, p. 67-88, setembro/dezembro de 2005 
são subordinadas a cumprirem o estatuto, suas deliberações, regulamentos e decisões acatadas pela Confederação Nacional.

Em contrapartida, poucos projetos e contribuições foram idealizados, selecionados ou até mesmo aprovados de maneira democrática e coerente por parte da $\mathrm{CBCa}$, visando o desenvolvimento e a massificação da canoagem nacional. As águas são assim "turbulentas", na busca dessa tão almejada massificação do esporte, e sua democratização.

Por outro lado, não podemos nos esquecer que a canoagem não pode ser vista apenas como esporte, quando muitas vezes valoriza-se somente a alta performance, mas também como lazer. E enquanto lazer, pelo seu próprio conceito que inclui a escolha do indivíduo, a livre adesão, deve agregar no seu conteúdo físicoesportivo, fatores fundamentais como a participação, envolvendo a garantia de oportunidades de participação necessitando, portanto, de políticas públicas, nos três âmbitos de atuação seja Municipal, Estadual ou Federal, articulados com outros segmentos da sociedade, procurando vencer as barreiras inter e intraclasses sociais que dificultam a sua prática.

É importante destacar que o estatuto da CBCa prevê a sua representação junto aos poderes públicos em geral (Capítulo III) e celebração de acordos ou convênios (Capítulo XIV), repasses de recursos públicos e compra de material de expediente e desportivo (Capítulo XVI), além de um aspecto fundamental que é o de "promover funcionamento de cursos técnicos do desporto sob sua direção", necessário para a formação de quadros, conforme dispõe o artigo $5^{\circ}$, do Capítulo III, letra "i".

\section{As políticas de atuação voltadas à propagação da canoagem e a necessidade de uma política nacional}

Desde a fundação da $\mathrm{CBCa}$, pouco foi apresentado, na perspectiva da propagação e desenvolvimento da modalidade no Brasil. Dentre os projetos apresentados, poucos foram duradouros.

No ínício da década de 1990, foi instituído pela CBCa o "Projeto Escolas", abrangendo todo o território nacional. Seu principal objetivo era fornecer embarcações para as cidades, clubes, associações, entre outras instituições interessadas em desenvolver a canoagem. Contava ainda com o auxílio da iniciativa privada, para que o preço das embarcações fosse reduzido em até 50\% facili-

Movimento, Porto Alegre, v. 11, n. 3, p. 67-88, setembro/dezembro de 2005 
tando, dessa maneira, adquiri-las (REVISTA CANOANDO, 1999). O material específico para a prática da modalidade foi assim adquirido (portanto uma importante etapa alcançada), contribuindo para desmistificar a concepção elitista que a canoagem carregava consigo, de ser acessível apenas a camadas mais privilegiadas da população em termos financeiros, que por sinal provocava empecilhos a muitos interessados, que confrontavam-se com essa barreira, em função do custo das embarcações não condizer com a realidade da maioria da população brasileira. No entanto, apenas uma das etapas foi fomentada no projeto, o acesso aos recursos materiais, nesse caso específico, as embarcações. Mas, existiam outras "correntezas" a serem vencidas, como: a necessidade de recursos para a própria manutenção do material, a falta de profissionais capacitados para a conduta das aulas, auxiliados, se preciso, por voluntários e, principalmente, a intervenção de políticas públicas municipais e até mesmo de instituições privadas locais, para que o projeto conseguisse "sobreviver", fato não ocorrido e desprezado pela CBCa.

Outro programa para a propagação da modalidade foi apresentado nove anos mais tarde, denominado "Rema Brasil". A proposta era de auxiliar as entidades locais que já desenvolviam qualquer modalidade da canoagem e incentivar outras a iniciarem-se em um novo meio esportivo, não convencional, para a maior parte da população brasileira. Durante os primeiros meses de desenvolvimento do projeto, a verba foi concedida às entidades filiadas (associações, clubes, prefeituras...). Depois, houve um corte abrupto, como relata a circular 158/99 enviada em 17 de novembro de 1999, pela CBCa, a todas entidades que integravam o projeto. Os repasses subseqüentes a essa circular nunca ocorreram, fazendo com que esse projeto não perdurasse mais que um ano, esbarrando nos mesmos empecilhos socioculturais apresentados no projeto anterior.

Isso demonstra a necessidade de uma política nacional para o esporte, que não o deixe à mercê de mudanças ocorridas local e regionalmente. Demonstra, ainda, a necessidade da busca de alternativas metodológicas de participação comunitária, tendo em vista a continuidade de programas e projetos, a despeito de mudanças de administrações.

Um bom exemplo de proposta de popularização das diversas modalidades esportivas naúticas, surgiu em 1999, com o antigo Instituto Nacional do Desenvolvimento de Desporto (INDESP), atualmente denominado de Secretaria Nacional do Esporte inaugurando o "Projeto Navegar". Envolvia a ampla relação entre profissionais de competência especíica das modalidades existentes (remo,

Movimento, Porto Alegre, v. 11, n. 3, p. 67-88, setembro/dezembro de 2005 
canoagem e vela) contribuindo para a capacitação de monitores no acompanhamento e treinamento dos jovens incluídos no programa. ${ }^{2}$ Durante os quatro primeiros anos do projeto (1999 - 2002) foram atendidos, em todo o Brasil, 14.280 crianças e adolescentes, nas três modalidades oferecidas. Assim, o "Projeto Navegar" fornecia um grande avanço para os esportes naúticos nacionais, fato jamais ocorrido na área naútica brasileira. Atualmente, com a mudança de Governo, o projeto está sendo reavaliado. ${ }^{3}$

Apesar da importante contribuição do trabalho integrado do Ministério do Esporte com as demais Secretarias Federais, tendo apoio das Confederações participantes (remo, canoagem e vela), essas mesmas confederações não devem se vincular, única e exclusivamente, somente a um projeto, mas sim, desenvolver e estimular outros projetos, na busca de incentivo e contribuição para suas respectivas modalidades, aumentando o número de adeptos nas atividades naúticas, num país que tem muito a oferecer nessa área, seja por meio do esporte educação, participação ou de alta performance.

O principal requisito para elevar ainda mais a canoagem nacional, em eventos de grande porte como campeonatos Pan-americanos, Mundiais e Olimpíadas, está diretamente envolvido com o tratamento que se fornece à iniciação do esporte, ou seja, a massificação esportiva constitui o principal alicerce para a propagação da modalidade, tanto qualitativamente quanto quantitativamente, para que ocorra, também, revelações de novos atletas, fornecendo, portanto, a importante oportunidade da participação esportiva como um fator de reinserção social.

Assim, a canoagem, enquanto atividade esportiva de participação, constitui-se como uma atividade de lazer dentro do seu conteúdo físico esportivo, podendo de inúmeras maneiras apropriarse de recursos lúdicos no exercício do seu aprendizado, fornecendo grandes contribuições à popularização do esporte.

2 ESPORTE. Disponível em: <http://www.esporte.gov.br/navegar> Acesso em: 2003

3 No entanto, devemos ressaltar que uma recente iniciativa da CBCa vem almejando a massificação da modalidade. O Projeto Segunto Tempo - Canoa Brasil, lançado em a massificação da modalidade. O Projeto Segunto Tempo - Canoa Brasil, lançado em 2004, tendo como principal proposta a abertura de 36 núcleos por todo território brasileiro, estabelecendo uma parceria entre Ministério do Esporte, Conselho Nacional da Criança e do Adolescente (CONANDA), CBCa, Prefeituras Municipai e Associações locais. O Projeto Segundo Tempo Canoa Brasil tem como objetivo proporcionar a parceria com as associações filiadas, e oferecer a prática da Canoagem, Vôlei de Praia e Futebol de Areia. Para maiores informações consultar $<$ http://www.cbca.org.br.>

Movimento, Porto Alegre, v. 11, n. 3, p. 67-88, setembro/dezembro de 2005 
Desta perspectiva, abordamos, no próximo item, como estudo de caso, o município de Piracicaba-SP, no qual a canoagem passou a ter uma inserção mais popular, por meio de uma Associação local, conveniada à Prefeitura Municipal, onde ambas conseguiram parcerias com empresas privadas, adquirindo os recursos físicos, materiais, e profissionais para o desenvolvimento do Projeto Desporto de Base (P.D.B.), objeto desta análise.

\section{Projeto Desporto de Base (P.D.B.) em Piracicaba - a partir da participação}

O Projeto Desporto de Base (P.D.B.), implantado na cidade de Piracicaba em 1989, iniciou uma nova diretriz para o esporte, viabilizando uma política esportiva municipal, no âmbito esportivo e de lazer, fornecendo a oportunidade aos munícipes, considerando seus direitos (GODOY et al., 1989).

Este projeto, acolhido pela extinta Secretaria de Esportes, Lazer e Turismo, atualmente denominada de Secretaria de Esporte, Lazer e Atividades Motoras (SELAM) difere-se de muitos programas esportivos vinculados ao poder público, marcados, quase sempre, pela gestão tradicional, conforme destacado por Zingoni (2003).

O município de Piracicaba, por meio da SELAM elaborou um programa de formação esportiva, buscando a garantia de oportunidades a todos os interessados, dentro de um processo educativo, tendo a evolução da performance como mera conseqüência das habilidades de cada indivíduo, adotando uma metodologia composta por três fases distintas, interligadas mas não necessariamente progressivas: 1) Fase I - Iniciação esportiva específica, enfatizando a promoção de atividades lúdicas; 2 ) Fase II - Aperfeiçoamento técnico específico; 3 ) Fase III - Treinamento de alto rendimento, aprimoramento da performance esportiva.

O P.D.B. propõe e desenvolve, ainda, um programa de animação interligada, ou seja, a realização de atividades esportivas (aulas e treinamentos), duas ou mais vezes na semana nos centros de treinamento, sendo denominada de ações freqüentes, contando com os eventos internos ou de apoio englobando as fases I e II, com a promoção de festivais envolvendo atividades competitivas e cooperativas entre os próprios núcleos e os eventos especiais ou de impacto abrangendo outras manifestações culturais de lazer.

Parte-se do princípio que a evolução será consequência para os alunos da fase I e II, respeitando, porém, o aprendizado motor

Movimento, Porto Alegre, v. 11, n. 3, p. 67-88, setembro/dezembro de 2005 
individualmente, pois assim a particularidade específica dos movimentos de cada modalidade será resultado da interação entre indivíduo e o meio ambiente, aprimorando-se as experiências colhidas ao longo dos anos de sua vida, provocando um desenvolvimento suas das capacidades próprias(OLIVEIRA, 1998).

Segundo Bonacelli e Soares (2001), as fases I e II do P.D.B. obtiveram até o ano de 2000, uma média de 4.300 participantes envolvidos com atividades físicas, nos diversos contextos, através de um trabalho diário, desenvolvido por 17 professores da SELAM, auxiliados por 20 estagiários de Educação Física, da Universidade Metodista de Piracicaba.

Concluindo o projeto, a fase III envolve atletas que vivenciaram as duas primeiras etapas e continuam a superar-se no aprimoramento, seja da performance em modalidades individuais ${ }^{4}$ ou coletivas, tanto nos treinamentos quanto em competições regionais, nacionais e internacionais, caracterizando o esporte como de alta performance.

Com esses pressupostos, Godoy et al. (1989) implantaram uma filosofia almejando a superação do simples divertimento por meio do esporte, possibilitando o desenvolvimento pessoal e social, bem como a passagem de um nível de prática elementar e conformista, para uma prática crítica e criativa, sendo a canoagem uma das diversas modalidades esportivas existentes.

Compreendemos, então, que para o desenvolvimento de qualquer modalidade esportiva, primeiramente é de extrema importância que a mesma se torne popular, contribuindo para a minimização das barreiras socioculturais, promovendo a participação em massa, elevando os níveis de participação elementar, caracterizado pelo conformismo ao inventivo, onde impera a criatividade, democratizando os espaços para a prática da modalidade (MARCELLINO, 2000). Nessa perspectiva, a canoagem deverá seguir os mesmos princípios.

4 Especificamente, a fase III do P.D.B. envolve as seguintes modalidades individuais: natação, karatê, pugilismo, capoeira, atletismo, xadrez, damas, ginástica rítmica, canoagem, tênis de mesa, tênis de campo. Como também, modalidades de caráter coletivo: futebol, basquetebol, futebol de salão, handebol, voleibol (BONACELLI E SOARES, 2001).

Movimento, Porto Alegre, v. 11, n. 3, p. 67-88, setembro/dezembro de 2005 
Projeto desporto de base na modalidade canoagem: preservando a formação esportiva enquanto garantia de oportunidade

Em 1989, adeptos da canoagem/lazer, em Piracicaba, criaram uma prova de caráter festivo, a fim de promover a modalidade no município. Esta prova tornou-se o marco para que a canoagem começasse a criar uma identidade com a população local.

Em 1991, a canoagem passou a integrar o rol de modalidades do P.D.B., no município de Piracicaba, filiando-se ao "Projeto Escolas" desenvolvido pela CBCa, recebendo o material adequado, tornando a cidade uma das pioneiras no Brasil a implantar uma modalidade de aventura, dentro do ciclo esportivo popular, surgindo, assim, a "canoagem popular", tendo como prioridade a reinserção social, procurando levar, os participantes, aos poucos, e aqueles que manifestassem interesse, aos níveis de esporte de participação e de competição (GODOY, et al., 1989).

Essa canoagem popular contribui para a massificação de um esporte com pouca tradição em nosso país; isso é um avanço para as atividades náuticas esportivas se considerarmos que existem vários esportes como a canoagem, que sofrem com a monocultura futebolística, acarretando dificuldades e um determinado voluntarismo, para a proliferação das demais atividades esportivas, no âmbito nacional.

A canoagem piracicabana ingressou no ciclo esportivo do P.D.B. quando este aderiu ao "Projeto Escolas", desenvolvido pela CBCa, em 1991, que passava a fornecer embarcações para que novas escolas se tornassem viáveis por todo o país. No entanto, conforme já destacamos anteriormente, falhas vieram a ocorrer causando empecilhos para que as entidades responsáveis pela canoagem se firmassem a longo prazo. Uma delas foi a falta de relações mais eficazes com o poder público municipal. Além disso, outras barreiras provocavam entraves, como as de faixa etária, tempo e espaços adequados para a prática, gênero, materiais específicos e suas devidas manutenções, falta de profissionais capacitados, falta de intervenção de empresas privadas (MARCELLINO, 2000), impossibilitando, assim, a propagação da canoagem nas vertentes lazer, esporte/participação ou esporte/competição.

Como vimos anteriormente, do ponto de vista legal, cabe à CBCa administrar os projetos por ela elaborados, como também estabelecer relações com as prefeituras de cidades com potencial

Movimento, Porto Alegre, v. 11, n. 3, p. 67-88, setembro/dezembro de 2005 
para o desenvolvimento e implantação da canoagem. Mas, para que as escolas tenham uma continuidade a longo prazo, as barreiras existentes nos programas propostos pela CBCa deverão ser superadas ou minimizadas e, nesse sentido, uma iniciativa interessante vem sendo desenvolvida em Piracicaba, com a implantação de associações locais, que passaram a dirigir a canoagem no município, além de constituírem o elo principa entre o poder público, as Federações Estaduais e a própria CBCa, conforme enfocamos mais adiante.

A canoagem, por sua vez, insere-se neste programa municipal de esporte e lazer, aderindo à mesma filosofia de trabalho realizada com as demais modalidades integrantes, aplicando, assim, os seus princípios básicos de participação e formação esportiva. Porém, ao atingir um excelente nível de organização e devido à necessidade de disposição espacial alternativa - necessidade de contato direto com o meio natural como rios e lagos passou a ser denominada de "Projetos Específicos por Modalida$\mathrm{de}^{\prime \prime}$, respeitando as fortes tradições culturais e geográficas peculiares ao município piracicabano, devido aos fortes vínculos com a presença do rio Piracicaba e do lago da Área de Lazer Municipal - pontos turísticos de grande representatividade para a cidade -, agregando lazer como forma de educação ambiental. Integra esses esforços, a Escola Municipal de Canoagem, num trabalho conjunto com o Clube Regatas de Piracicaba, e com a contribuição voluntária por meio de Pais e Amigos da Canoagem, e é considerada uma escola modelo em nível nacional, servindo de parâmetro para o desenvolvimento de outros pólos nessa modalidade, de acordo com os dados da Revista Esporte, Turismo e Lazer (1992). Desde então, a canoagem foi inserida nas atividades esportivas municipais com a intenção de fortificar-se a cada ano.

No entanto, com a troca da administração municipal em meados de 1993, a modalidade passou por maus momentos, pois o compromentimento do novo governo municipal com o esporte piracicabano não permaneceu o mesmo, afetando os projetos esportivos de uma maneira geral, ocorrendo, portanto, um certo declínio nas modalidades, inclusive na canoagem, por situar-se no Projeto Desporto de Base. Assim, a canoagem piracicabana entre 1993 e 1996 entrou em uma fase de estagnação em termos de participação popular. Em contrapartida, atletas que se encontravam na fase de alta performance do projeto, persistiram representando o município em provas estaduais e campeonatos brasileiros, sendo selecionados para integrarem a equipe brasileira em provas internacionais.

Movimento, Porto Alegre, v. 11, n. 3, p. 67-88, setembro/dezembro de 2005 
Diante da situação, esses mesmos atletas de alta performance e seus pais, interessados na modalidade, além de voluntários e adeptos da canoagem restabeleceram, em 1997, relações com o poder público, primeiramente envolvendo-se com o convênio firmado entre a Prefeitura Municipal de Piracicaba e a Universidade Metodista de Piracicaba, pela qual, alunos do curso de Educação Física ministrariam, como forma de estágio supervisionado, a modalidade canoagem, no município. Coincidentemente, esses estagiários integraram o P.D.B., na posição de alunos, no respectivo projeto, anos antes.

Assim, as aulas recomeçaram elevando a participação popular, no lago da Área de Lazer Municipal, apropriando-se do esporte como instrumento a ser utilizado como componente lúdico da cultura, principalmente nas categorias iniciais, como manifestação de lazer, possibilitando o ingresso gratuito de cidadãos interessados pela prática da modalidade, concomitantemente ao poder público fornecendo as necessárias condições de como utilizá-lo.

Dessa forma, o envolvimento do poder público, em parceria com entidades privadas, prociciou o crescimento da modalidade em âmbito municipal: a partir de 1997 a canoagem, no período de um ano, já adquiria, aproximadamente, cinqüenta alunos semanalmente. A modalidade havia alcançado um bom nível de desenvolvimento e necessitava de reestruturação. Com base nesse fato, os integrantes da canoagem foram orientados, por meio do próprio poder público, a fundar uma associação que visasse defender os interesses da modalidade. No dia 15 de janeiro de 1998, fundouse, oficialmente, a ASCAPI - Associação de Canoagem de Piracicaba (ASCAPI), cujo art. $2^{\circ}$ de seu Estatuto prevê: "A finalidade única e exclusiva da difusão entre os sócios ${ }^{5}$ da prática da canoagem, promovendo a realização de torneios internos, participando de competições oficiais e amistosas".

Sua fundação foi incentivada pela lei municipal $\mathrm{n}^{0} 7510,05$ de março de 1997, que regulamentou a lei no 4203/96, que: “Dispõe sobre cooperação com particulares interessados em colaborar com o Poder Público na conservação de espaços públicos destinados à prática de esporte" e dá outras providências. Dentro da lei vigente,

5 Cabe ressaltar que o estatuto da Associação de Canoagem de Piracicaba prevê: "A finalidade única e exclusiva da difusão 'entre os seus sócios' da prática da canoagem". Em contrapartida a prática da canoagem se estende a todos interessados, noagem". Em contrapartida a prática da canoagem se estende a todos interessados, poder público municipal, e aderir as políticas do Projeto Desporto de Base.

Movimento, Porto Alegre, v. 11, n. 3, p. 67-88, setembro/dezembro de 2005 
contribuições significativas foram conquistadas, ao estabelecer um convênio com o poder público, conseguindo-se angariar recursos financeiros que foram utilizados para a compra e manutenção do material e do espaço utilizado para o desenvolvimento das aulas e treinamentos e a filiação da Associação e dos atletas aos órgãos de administração da modalidade.

Além disso, a partir de 19 de novembro de 1992, o poder público passou a regulamentar a lei $\mathrm{n}^{0} 3531$, visando contribuições do poder privado, assegurando incentivo fiscal, para a realização de projetos relativos ao esporte amador de competição.

As interfaces dentro do poder público municipal, ou seja, as relações estabelecidas inter-secretarias também foram de fundamental importância. Nesse caso específico podemos citar algumas que se envolveram mais diretamente: Secretaria Municipal de Transportes Internos ${ }^{6}$ (SEMUTRI), Secretaria de Defesa do Meio Ambiente (SEDEMA) devido aos locais utilizados para a prática da canoagem como o lago da Área de Lazer Municipal e o próprio rio Piracicaba serem de responsabilidades dessa secretaria, Secretaria Municipal de Obras (SEMOB), auxiliando na construção e adequação do local para prática da modalidade, etc.

Em conjunto com as medidas supracitadas, estabeleceu-se uma política para a formação de quadro de professores, para que as aulas de canoagem fossem retomadas. Isso não foi cercado de maiores dificuldades, uma vez que a modalidade contava com atletas que cursavam a Faculdade de Educação Física-UNIMEP, conseguindo se inserir no programa de bolsa estágio do Projeto Desporto de Base, ou como atletas-bolsistas, representando Piracicaba em competições oficiais, havendo em ambos uma política de recursos humanos promovida num convênio firmado entre a Prefeitura Municipal de Piracicaba e a Faculdade de Educação Física-UNIMEP (BONACELLI E SOARES, 2001).

Todas essas medidas foram asseguradas por um convênio firmado em janeiro de 1998, entre a recém fundada Associação de Canoagem de Piracicaba e a Prefeitura Municipal, que visava, o desenvolvimento de modalidades esportivas, podendo se constituir na forma de equipamentos, materiais, bolsas de estudo, repasse de verbas com prestação de contas, espaços para treinamentos, estágios e outros.

6 Cabe ressaltar que na canoagem, o transporte não se restringe somente aos atletas, mas, também, inclui as embarcações. Esse aspecto, muitas vezes, provoca grandes empecilhos para as viagens.

Movimento, Porto Alegre, v. 11, n. 3, p. 67-88, setembro/dezembro de 2005 
Assim, a canoagem, no município, retomava a participação popular, ao reatar relações com o poder público municipal, envolvendo-se, novamente, no Projeto Desporto de Base e procurando, assim, minimizar as barreiras socioculturais para o seu desenvolvimento.

Dessa forma, poder público, professores, estagiários e associação municipal, solidificaram relações em prol da canoagem, constituindo em termos de quadros para atuação uma estrutura que se assemelha a estrutura de animação piramidal proposta por Marcellino (2003), baseado em Dumazedier (s/d), ou seja, no vértice encontramos os coordenadores do Projeto Desporto de Base, tidos como animadores socioculturais de competência geral; na porção intermediária temos os professores e estagiários, animadores socioculturais de competência específica, no caso o conteúdo físico esportivo canoagem e, por fim, na base, animadores socioculturais voluntários, pessoas que já se envolviam com a canoagem, pais de atletas, adeptos da canoagem lazer, que passaram a integrar a Associação Municipal da modalidade.

A propagação da canoagem, em conjunto com os demais esportes, tornou-se exequível a partir da Lei Orgânica do Município de Piracicaba - (3531/92) artigo 267/89, que afirma: “caberá ao município apoiar e incentivar as práticas esportivas... como direito de todos". O artigo 268/89 aborda o apoio e o incentivo ao lazer, como forma de integração social, e ações que visem: " II - ao esporte educacional, comunitário, de base e competitivo(...); III - a construção e manutenção de espaços equipados para as práticas esportivas (...) e de lazer. IV - a criação de programas populares de esportes $(\ldots)$ orientados a servir as populações de baixa renda (PIRACICABA, 1992).

Todas essas medidas, contribuiram diretamente para a propagação da modalidade, envolvendo as fases I - Iniciação e participação e fase II - aperfeiçoamento das aulas e treinamentos. Todavia, o esporte dentro das suas manifestações envolve, da mesma forma, a alta performance, não sendo diferente no Projeto Desporto de Base, e também na específica canoagem.

O seleto grupo, integrante da alta performance da canoagem piracicabana, foi formado por atletas provenientes das categorias de base (fases I e II), fato não muito comum no esporte de rendimento, em que as contratações de atletas tornaram-se um mercado, e que ocorria, também, no mesmo município de Piracicaba até o ano de 1988, priorizando a "importação" de atletas de outros muni-

Movimento, Porto Alegre, v. 11, n. 3, p. 67-88, setembro/dezembro de 2005 
cípios, com a intenção de fornecer uma "maior representatividade" ao esporte municipal, evidenciando as reais intenções das políticas "públicas" (se assim podemos considerá-las novamente) descritas por Godoy et al. (1989, p. 65). Porém, a formação de uma equipe de canoagem com grande representatividade, tanto nacional quanto internacional, somente foi possível devido à política de atuação instituída em 1989 pelo Projeto Desporto de Base, com a "inversão de prioridades".

Portanto, o núcleo de canoagem em Piracicaba havia se reestruturado, sendo administrado por uma Associação local (ASCAPI), desenvolvendo a canoagem em três fases, dentro de um projeto desportivo popular municipal.

O programa de animação, interligado ao Projeto Desporto de Base, especificamente na canoagem, conta com ações freqüentes, retratando as aulas e os treinamentos da canoagem durante a semana e nos finais de semana, seguido pelos eventos de apoio, festivais esportivos estipulados por regras adaptadas, quando competitivos, visando enfocar os conteúdos apresentados nas aulas, envolvendo, principalmente, os alunos da fase I. Esta ação pretende reforçar o prazer pela prática da canoagem, possibilitando a inclusão social por meio de eventos de pequeno porte. Estes eventos, na canoagem, podem ser exemplificados pelo passeio de caiaque que o município realizou em 1991 envolvendo aproximadamente 600 adeptos da canoagem lazer/participativa, deixando claro a forte relação cultural entre o rio e a população local (MOURÃO, 2001). Integram, ainda, o programa os eventos de impacto, realizados em parceria com a Federação Paulista de Canoagem (FPCa). Dessa forma, tornou-se possível a realização de torneios regionais e estaduais, com a participação de alunos que encontravam-se na fase II do projeto, assim como os da fase III (GODOY et al., 1989).

Este programa de animação interligada, envolvendo as fase I com as ações freqüentes e a fase II com os eventos de apoio, passa a ser, também, uma responsabilidade da Associação para com seus associados, como prevê a cláusula terceira, dos contratos firmados anualmente: "A ENTIDADE deverá, em parceria com a SELAM realizar um evento anual de canoagem no Município com o objetivo de divulgar a modalidade".

O esporte de alta performance representado pela fase III no Projeto Desporto de Base, visando aprimoramento das capacidades esportivas (técnico, táticas, físicas, psicológicas...) utilizadas nos eventos de grande porte, faz com que o atleta esteja em contato permanente com a modalidade, além de envolver gastos mais ele-

Movimento, Porto Alegre, v. 11, n. 3, p. 67-88, setembro/dezembro de 2005 
vados, em função da carga de treinamento ser maior e mais específica, maior número de competições anuais, equipamentos mais sofisticados, alta seletividade para ingresso em seleções de caráter nacional, tendo que, muitas vezes, se desvincular de algumas obrigações sociais e até mesmo de trabalho em alguns casos, entre outros fatores que integram o esporte de alta performance.

Em decorrência disso, o P.D.B. visa criar uma estrutura para que atletas das mais variadas modalidades (inclusive a canoagem), possam representar o município nesses grandes eventos. Porém, não compete ao poder público "patrocinar" tais modalidades ao atingirem esta fase, mas viabilizar acessos ou firmar parcerias com a iniciativa privada, para que tais atletas integrantes desse estágio de treinamento sejam apoiados (GODOY et al., 1989). Um bom exemplo, foi o sancionamento da Lei Orgânica Municipal no 3531, em 19 de novembro de 1992, que no seu art. $3^{\circ}$ institui incentivo fiscal para a realização de projetos culturais ou relativos ao esporte amador de competição, ou seja, concede descontos tributários municipais às entidades (independente da sua natureza) que incentivem as atividades físico-esportivas de caráter amador no município.

Este incentivo às atividades esportivas de caráter amador, de acordo com o artigo $3^{\circ}$, parágrafo $2^{\circ}$, pode se constituir para pagamento de pessoal especializado, garantindo que treinadores permaneçam e trabalhem com tais modalidades, aquisição de materiais específicos, já que os equipamentos dos esportes de alta performance dependem de maiores gastos, viagens por serem mais longas necessitam de uma maior permanência para treinos entre outras adaptações e taxas de filiação. É notável que tais recursos possam auxiliar, também, as fases de iniciação e aperfeiçoamento, contribuindo para minimizar algumas barreiras socioculturais.

O incentivo fiscal, proposto pela Lei Orgânica Municipal no 3531/ 92, tem como vinculador o poder público, ao expedir certificados referentes ao valor de incentivo, em função da arrecadação do Imposto sobre Propriedade Predial e Territorial Urbana (IPTU), autorizados pelo Poder Executivo. Porém, relatórios anuais de prestação de contas das despesas gastas para com a modalidade são apresentados pelas entidades administrativas da modalidade, ao Conselho responsável pela orientação e fiscalização do projeto, além da entidade ser, obrigatoriamente, filiada à Federação Estadual da modalidade.

Todo o crescimento da canoagem Piracicabana, foi alicerçado por entender o esporte como um fator de reinserção social, oportunizando a prática esportiva à toda a população, dentro das ações freqüentes e eventos de apoio propostos pelo Projeto Desporto de

Movimento, Porto Alegre, v. 11, n. 3, p. 67-88, setembro/dezembro de 2005 
Base, passando, conseqüentemente, a ter uma forte equipe competitiva de alta performance com integrantes da seleção nacional na modalidade slalom, aderindo, também, a outras modalidades envolvidas com corredeiras, como rafting de competição, descida, rodeo.

Ademais, sua principal representatividade deve-se ao elevado número de participantes em provas estaduais e nacionais, constituindo-se como uma das maiores equipes do país, efeito reflexo do desenvolvimento da reinserção social utilizando-se do conteúdo físico esportivo como atividade de lazer a serem vivenciadas, pela população.

Com uma associação legalmente constituída, todas as propostas, projetos e iniciativas ganharam uma maior atenção. Além de aumentar a possibilidade de angariar recursos públicos e privados, está se demonstrando, ao longo do processo, o alcance das iniciativas individuais, considerando o fato de que a responsabilidade pelo desenvolvimento da modalidade deve-se aos envolvidos com a mesma, sejam eles voluntários, atletas independente da fase de treinamento que se encontram, amantes ou profissionais atuantes com a modalidade. ${ }^{7}$

Devido à capacidade demonstrada pelos estagiários, os conteúdos programáticos foram se aperfeiçoando paralelamente à filosofia do P.D.B., ocorrendo uma quebra de paradigmas no aprendizado da canoagem, pois a modalidade até então era aplicada na maioria dos centros de aprendizado que existiam pelo Brasil, com a finalidade de formar futuros atletas, com uma carga de treinamento elevada e exaustiva, ao invés de transformar o caiaque em um instrumento lúdico. ${ }^{8}$ Dentro dessa nova concepção, as aulas nas suas duas primeiras fases são voltadas para a manifestação das atividades lúdicas e recreativas no aprendizado da canoagem, vindo a ter uma carga mais elevada de treinamento da fase III, sempre em busca do caráter educacional (GODOY et al., 1989).

7 CANOAGEM. Disponível em:<http:// www.canoagem.org.br/criarassoc(asp) > . Acesso em: 2003

8 A introdução do "conhecer lúdico" é recomendada por Gaio (1996, p. 21), especificamente para a popularização da modalidade Ginástica Rítmica., do P.D.B. ao propor "[...] um conteúdo programático com o objetivo de estimular o desenvolvimento da criança, que propicie novas experiências de movimentos (do natural ao construído), que desperte a criatividade através do 'conhecer lúdico' da G.R.[...]".

Movimento, Porto Alegre, v. 11, n. 3, p. 67-88, setembro/dezembro de 2005 


\section{As fortes correntezas das barreiras socioculturais}

As barreiras socioculturais (MARCELLINO, 2000) apresentamse das mais diferenciadas maneiras no lazer, porém, tendo fatores que causam empecilhos à prática esportiva de alta performance como: a problemática disposição de tempo e espaço específico para a prática, aspectos econômicos, obrigações referentes ao trabalho e à família, material apropriado, entre outros, que provocam a falta de condições disponíveis e adequadas para que os programas de treinamento sejam realizados eficientemente, intercalando as sessões de esforço e os respectivos e necessários intervalos de descanso.

Dentre essas barreiras podemos destacar o ingresso nos estudos acadêmicos, levando atletas a se deslocarem das cidades onde desenvolvem seus treinamentos, impossibilitando de continuá-los em outros municípios, pela falta do espaço apropriado para a prática da modalidade canoagem "slalom", rios específicos, estruturas físicas, profissionais especializados, todos fundamentais para o desenvolvimento dos treinamentos. Estes espaços apropriados não são encontrados com tanta facilidade como é o caso de esportes mais populares como a natação, apesar de compreendermos as extremas dificuldades que os esportes amadores sofrem, em geral, no Brasil.

Outra barreira encontra-se em função do trabalho, devido à canoagem slalom ser extremamente amadora para a esmagadora maioria que a pratica, tendo estes atletas a difícil missão de administrar uma boa parcela do tempo, entre o trabalho e a realização dos treinamentos, além do desgaste promovido por ambos. No entanto, o caráter amador não é vinculado somente aos atletas, mas, também, aos treinadores, demais integrantes e comissões técnicas. No Brasil, poucos são os esportes em que os treinadores se asseguram financeiramente do trabalho exclusivo desenvolvido para o esporte, dificultando, ainda mais, a busca de um trabalho interdisciplinar (fisioterapeuta, nutricionista, fisiologista, etc.).

Com a canoagem não é diferente. Um bom exemplo a ser citado, é o slalom, que começou a se desenvolver em 1987 no Brasil; portanto, uma modalidade extremamente nova, mas que já começa a dar os seus primeiros passos para o ingresso no mundo esportivo de alta performance. No entanto, não encontramos muitos profissionais que atuam como treinadores, sendo esta uma das peças fundamentais para o desenvolvimento, renovação e propagação do esporte (SELBACH, 1999).

Movimento, Porto Alegre, v. 11, n. 3, p. 67-88, setembro/dezembro de 2005 
Nesses dezoito anos da existência do slalom, no Brasil, nos certificamos que três gerações, pelo menos, de atletas e treinadores vieram a se formar, porém, foram poucos os que persistiram a continuarem envolvidos com o meio esportivo, seja profissionalmente, ou de maneira voluntária. Constatamos a falta de uma política de atuação por parte da CBCa, visando à formação e capacitação de treinadores nacionais para, futuramente, desenvolverem uma identidade esportiva com características próprias.

Notamos, ainda, uma falta de vínculos mais sólidos, seja por parte dos órgãos administrativos como das Federações e Confederação, ou mesmo das Administrações Públicas, com o setor privado, que dificulta a proliferação do esporte-lazer, esporteparticipação e, principalmente, de alta performance, devido ao alto custo despendido para a sua manutenção.

Devemos ressaltar que qualquer atividade físico-esportiva de alta performance depende de um gasto maior com o material, devido à especificidade e qualidade do mesmo. Isto ocorre na intenção de possibilitar inúmeras vantagens que resultam, e muito, na performance final do atleta. Entretanto, esses materiais, na grande maioria das vezes, são adquiridos pelos próprios atletas, que passam a incluir esses gastos com o esporte na sua vida cotidiana, gerando assim, mais uma dificuldade a ser sanada nas difíceis correntezas no cotidiano dos esportes amadores brasileiros.

Diante de todas as barreiras impostas aos praticantes das atividades físico-esportivas, de caráter amadora em nosso país, as demais modalidades ainda sofrem a concorrência do que pode ser caracterizado como monocultura do futebol.

Apesar disso tudo, vivemos numa sociedade em que as cobranças são extenuantes; somos valorizados em função do que produzimos; não nos interessamos pelo processo, e somos cobrados pelo resultado final. Dentro dessas concepções Medina (1992) vai além, ao afirmar que as forças econômicas predominam sobre as práticas produtivas, culturais e sociais. Com o esporte não poderia ser diferente; a sociedade cobra todos os valores impostos, sem que os mesmos sejam refletidos; as cobranças pelas conquistas são excessivas; a mídia contribui, em muito, dentre as inúmeras pressões sofridas pelos atletas no qual somente o vitorioso é valorizado, esquecendo-se, no entanto, das dificuldades constantes que os esportes amadores enfrentam no Brasil. Porém, esses esportes amadores entre os quais incluímos a canoagem, sobrevivem no nosso território, apesar das dificuldades impostas.

Movimento, Porto Alegre, v. 11, n. 3, p. 67-88, setembro/dezembro de 2005 
Podemos perceber, pela análise dos documentos do Projeto Desporto de Base uma ligação evidente entre as vertentes esporte/ lazer, esporte/participação, e esporte/competição, no P.D.B., de Piracicaba, na modalidade canoagem, que mesmo quando houve mudança de administração, não sofreu solução de continuidade. Isso prevaleceu tendo em vista o envolvimento de seus quadros: dirigentes, professores, estagiários e voluntários. Mais ainda, a partir da percepção dos estagiários, pois o projeto foi modificado criativamente, incorporando o componente lúdico da cultura, enquanto metodologia de ensino-aprendizagem, principalmente na fase I. Contudo, ainda não se percebe a vinculação desse projeto com os órgãos específicos da canoagem esportiva e com os outros âmbitos de governo (Estadual e Federal).

Diante das turbulentas correntezas administrativas a serem enfrentadas pela canoagem brasileira enquanto esporte, das dificuldades impostas pelas barreiras socioculturais para a modalidade como lazer, e das incipientes políticas públicas na área, procuraremos atingir águas mais calmas, na busca pela popularização, com remadas sincronizadas entre Poder Público e Privado, Sociedade Civil Organizada, e Órgãos administrativos da modalidade (Federações Estaduais e Confederação).

\section{Considerações finais: em busca de águas calmas}

Do estudo concluímos que, só podemos remar das águas turbulentas das barreiras socioculturais, que, atualmente impedem a popularização da canoagem brasileira, para as águas calmas de sua democratização, através de um esforço conjunto de remadas que incluem: 1) a elaboração de uma política pública municipal, dentro dos critérios já elencados; fato ocorrido no município de Piracicaba através do Projeto Desporto de Base. Mesmo a canoagem sendo considerada por muitos como uma modalidade "não convencional", passou a integrar o campo esportivo desse município; 2) a vinculação dessa prática aos órgãos representativos da canoagem nacional (Federações e Confederação); tendo a Associação de Canoagem de Piracicaba como órgão mediador entre o Poder Público Municipal e os devidos órgãos administrativos; 3 ) a ligação da Política Municipal às outras esferas do poder (Estadual e Federal); como parcerias estabelecidas entre o Poder Público Municipal com a Secretaria da Juventude, Esporte e Lazer do Estado de São Paulo, bem como junto ao Ministério do Esporte 
em âmbito nacional; 4) a ligação da Política Municipal à sociedade civil; como a criação da Associação de Canoagem de Piracicaba, entidade responsável pelo desenvolvimento na canoagem em Piracicaba.

Nesse último aspecto é importante destacar, dois pontos fundamentais: a) o funcionamento de uma Associação como elo de ligação entre os órgãos públicos, os órgãos representativos do esporte e a sociedade em geral, e b) a formação de uma estrutura de animação, como descreve Marcellino (2003).

Canoeing as a popular sport. The case of piracicaba Abstract: Canoeing has come from popular culture as a utilitarian or play activity. Today in our society it has become a leisure and sport. But it needs public policies to be democratized, since there are socio-cultural barriers to development. The experience of Piracicaba$\mathrm{SP}$, here analyzed, from a case study focus on documental contents that show that this is possible, if canoeing is integrated in the Municipal public policies of sport and leisure. In this last aspect it is seen in its first phases from its cultural components of play.

Keywords: leisure, sport, public policies, canoeing.

La popularización de la canoagen: el caso de piracicaba

Resumen: De oriundo del cotidiano de la cultura popular, sea como la actividad, sea como la actividad ludica, la canoagen se inserta hoy, como ocio y deporte, en la sociedad, pero necesita de las políticas publicas para ser democratizada, teniendo en la vista una serie de vallas socioculturales que cercan sus desarrollos. La experiencia de Piracicaba-SP, aquí analizada, a partír del estudio del caso, baseado en la analize del contenido documental, demuestra que eso és posible se la canoagen fuera introducida en una política publica municipal del desporto y ocio, y neste ultimo aspecto encarada en suyas primeras fases, a partír del componente ludico de la cultura.

Palabras-clave: ocio, deporte, políticas publicas, canoagen.

Movimento, Porto Alegre, v. 11, n. 3, p. 67-88, setembro/dezembro de 2005 


\section{Referências}

ARIÉS, P. História social da criança e da família. 2a .ed., Rio de Janeiro: Zahar,1976.

BONACELLI, M. C. ; SOARES, C.A.F. Desporto de Base: Secretaria de Esportes, Lazer e Atividades Motoras - Prefeitura de Piracicaba. In. ANJOS, LUIZ dos (org.): Políticas Públicas de Esporte e Lazer: Experiências e Perspectivas. Piracicaba: Unimep,2001.

BRUYNE, P; HERMAN, J. SCHOUTHEETE, M. Dinâmica da pesquisa em ciências sociais. $5^{\text {a }}$ ed. Rio de Janeiro: Francisco Alves, 1991.

CAILLOIS, R. Os jogos e os homens: Lisboa: Gallimard, 1990.

CANOAGEM. Disponível em: <http://www.canoagem.org.br/criarassoc(asp)>. Acesso em: 2003.

CURITIBA. Estatuto da Confederação Brasileira de Canoagem. 2003.

DUMAZEDIER, J. Questionamento teórico do Lazer. Porto Alegre. CELAR, s.d. ESPORTE. Disponível em: <http://www.esporte.gov.br/navegar> Acesso em: 2003.

GAIO, R. Ginástica Rítmica "popular": uma proposta educacional. São Paulo: Robe, 1996.

GIL, A C. Métodos e Técnicas de Pesquisa Social. $3^{\circ}$ ed. São Paulo: Atlas, 1991. GODOY. J., et al. Desporto de Base. Piracicaba: Unimep, 1989.

HUIZINGA, Johan. Homo Ludens: o jogo como elemento da cultura. São Paulo: Perspectiva, 1993.

MARCEllino, N.C. Pedagogia da Animação. Campinas: Papirus, 1990.

_. Estudos do lazer; uma introdução. $2^{\mathrm{a}}$ ed. Campinas: Papirus, 2000.

_. (org). Formação e Desenvolvimento de Pessoal em Lazer e Esporte: Para atuação em Políticas Públicas. Campinas: Papirus, 2003.

MEDINA, J. P. S. Reflexões sobre a fragmentação do saber esportivo. In MOREIRA, W. W. Educação Física e Esportes: perspectivas para o século XXI. Campinas, SP: Papirus, 1992.

MOURÃO, J.O.F. Piracicaba 2010- realizando o futuro. Piracicaba:Piracicaba 2010, 2001.

OLIVEIRA, Marcelo de. Desporto de Base - A importância da escola de Esportes. São Paulo: Ícone, 1998.

PERROTI, E. A criança e a produção cultural. In. ZILBERMAN, R. (org.) A produção cultural para a criança. Porto Alegre: Mercado Aberto, 1982.

Movimento, Porto Alegre, v. 11, n. 3, p. 67-88, setembro/dezembro de 2005 
PIRACICABA. Prefeitura Municipal de Piracicaba. Coordenadoria de Esportes. Plano da Coordenadoria de Esportes de Piracicaba - Projeto para o Desporto Piracicabano, 1989.

PIRACICABA. Prefeitura Municipal de Piracicaba. Lei 3531/92.

PIRACICABA. Prefeitura Municipal de Piracicaba. Lei 7510/97.

PIRACICABA. Estatuto da Associação de Canoagem de Piracicaba, 1998 PROJETO SEGUNDO TEMPO - CANOA BRASIL. Disponível em: < http:// www.cbca.org.br>. Acesso realizado em 28.08.2005.

REVISTA CANOANDO. Revista Oficial da Canoagem Brasileira. Estrela: Ed. L/A design, Ano I - nº 2, 1999.

REVISTA ESPORTE LAZER E TURISMO - O Direito e a alegria. Secretaria de Esportes Lazer e Turismo. Piracicaba, 1992.

SELBACH, Gustavo. Na onda da canoa. Federação de Canoagem do Estado do Rio Grande do Sul. Rio Grande do Sul, ano 2, n 5, dez 1999.

TEREZANI, D.R. Popularização da Canoagem como Esporte e Lazer- o caso de Piracicaba. Dissertação de Mestrado. Piracicaba, Curso de Mestrado em Educação Física, UNIMEP, 2004.

ZINGONI, P. Descentralização e Participação em Gestões Municipais de Esporte e Lazer. In. ISAYAMA, H. F., WERNECK, L. G. (org.) Lazer, Recreação e Educação Física. Belo Horizonte: Autêntica, 2003.

* Professor de Graduação e Pós-Graduação na UNIMEP. Líder do Grupo de Pesquisas em Lazer. Apoio: CNPq.

** Mestre em Educação Física pela UNIMEP.

Movimento, Porto Alegre, v. 11, n. 3, p. 67-88, setembro/dezembro de 2005 